\title{
Movement and retention of polychlorinated biphenyls in a paddy field of WenTai area in China
}

\author{
Xinhui Bi, Shaogang Chu, Qingyu Meng, Xiaobai Xu* \\ Research Center for Eco-Environmental Sciences, Chinese Academy of Sciences, Beijing 100085, China
}

Received 12 May 2000; received in revised form 22 February 2001; accepted 12 March 2001

\begin{abstract}
Polychlorinated biphenyls (PCBs) are classified as priority pollutants by environmental agencies. A field investigation on polychlorinated biphenyls movement and retention in paddy field was conducted during 1993, 1997 and 1999 at the WenTai area. Soil, air and rice samples were analyzed. PCB concentrations in the soil showed a reducing trend with respect to time and depth. Most of the di-, tri-, and tetra-chlorinated PCB congeners showed significant decreases during the period, while the more highly chlorinated PCBs were more persistent in soil. The results of field investigation data showed that even though 6 years the PCB concentrations in two fields were far from reaching uniform. In addition, rice grown in the field appeared somewhat contamination by PCBs, but it was not likely subjected to concentrating PCBs from contaminated soil significantly. It was shown that the PCB concentrations in rice samples were not directly proportional to their concentrations in soil. Principal component analysis was performed with the standardized relative abundance of PCBs in the samples. All these observations indicated that the pattern of PCBs in soil cannot be considered to reflect the original pollution source. (C) 2002 Elsevier Science B.V. All rights reserved.
\end{abstract}

Keywords: PCBs; Rice; Transport; Bioconcentration; Soil; Paddy; China

\section{Introduction}

Polychlorinated biphenyls (PCBs) have attained considerable notoriety as ubiquitous environmental contaminants(WHO, 1993). Despite that their industrial use in many industrialized countries has been restricted since the 1970s. The subsequent disposal or dumping in landfills of PCBs has resulted in universal contamination of air, water and soil, etc. (Iwata et al., 1994). They have been included in the "priority pollutants" listings implemented by the US Environmental Protection Agency (USEPA) and by the Euro-

\footnotetext{
* Corresponding author. Tel.: +86-10-62919177; fax: +86-10-62562877.

E-mail address: xuxb@public.bta.net.cn (X. Xu).
}

pean Commission. These compounds have also been considered for inclusion in the priority pollutant list of the State Environmental Protection Administration (SEPA) in China.

The chemical formula of PCBs can be presented as $\mathrm{C}_{12} \mathrm{H}_{10-n} \mathrm{Cl}_{n}$, where $n$ is the number of chlorine atoms within the range of 1-10. Theoretically, 209 congeners are possible, but only about 130 congeners are likely to be found in commercial products. All congeners of PCBs are low volatile and highly lipophilic, with the consequence that more than $99 \%$ of the environmental PCBs mass are found in soil. As organic pollutants, the most important aspects of the environmental behaviors of PCBs in soil are their disappearance rate by various mechanism, translocation from soil into plant tissues, and accumulation in the food 
chain. Marked dissimilarities in the rate and extent of PCBs sequestration are found in different types of soil (Chung and Alexander, 1998). It is generally agreed that human diet represents the main route of human exposure to PCBs. Because of their ability to biomagnify through the food chain and our relative topmost position in the food chain, the occurrence of PCBs in various types of food has been widely studied. Dietary intake with meal, fish and milk has been identified as the principal route of human exposure to PCBs (Jan and Adamic, 1991; Kannan et al., 1994; Ocker and Eich, 1992; Schecter et al., 1997; Theelen et al., 1993). However, The plant is the first link in the food chain.

Knowledge of the behavior of polychlorinated biphenyl congeners in natural flora and crop species in essential in elucidating their bioaccumulation in the food chain. There are only few studies of PCBs uptake by terrestrial plants, and they were mainly conducted under simulated conditions in growth chambers or green-house with spiked compounds (Webber et al., 1994). At present, it is suggested that the pathway of PCBs accumulation in plants might include: root uptake and transport to the shoot; contamination of shoots by soil particles and atmospheric deposition. Laboratory studies indicating uptake and translocation of PCBs via the root systems of plant have been reported by some workers (Suzuki et al., 1977). However, conflicting evidence suggests that PCBs uptake and transfer by crops is probably not a real transfer via the root system but only a partitioning process (Offenbaecher, 1992). There are major differences on the accumulation and transport behavior of PCBs by specific plants. Some terrestrial plants such as purple loosestrife (Lythrum salicarial), may accumulate PCBs via the root system (Bush et al., 1986). Other species, such as beans (Phaseolus spp.), may show no consistent increase over time (Bacci and Gaggi, 1985), while corn (Zea mays L.) even reduced their PCBs burdens over time (Shane and Bush, 1989). Some experiments reported that the atmospheric deposition was of far greater important pathway than soil-plant transfer for the accumulation of PCBs in plant (Muller et al., 1993).

Rice (Oryza sativa) is the predominant crop grown in south of China. As more than half of cropland in the area is paddy field, the movement and retention of PCBs under a paddy field system is an important concern. Not only is rice the main food of humans, but also it is used widely as a livestock feed. An estimate of the amount of PCBs present in various ecological systems is important for the contaminated area and the remediation process. The aim of this work was to investigate the PCB concentrations in a system in the WenTai area. The movement and retention of PCBs in the system and the possible pathway of PCBs accumulation in rice were investigated.

\section{Materials and methods}

\subsection{Sample collection}

Samples were collected from a contaminated paddy field in WenTai area, located at $28^{\circ} \mathrm{N}, 120^{\circ} 45^{\prime} \mathrm{E}$, in Zhejiang Province of China (Table 1). The soil was classified as Udic Ferrisols. In 1989, some arbitrary disposal of used electric appliances resulted in the PCBs pollution accident. There was no other PCBs pollution source near this area, so it offered an ideal place to study the movement of PCBs in the environmental system.

Soil and rice samples were collected in 1993, 1997 and 1999. Air samples (including the vapor and particulate) were collected in 1999. Soil samples were taken from a paddy field (Sites A and B) in which Site A was about $100 \mathrm{~m}$ long and $30 \mathrm{~m}$ wide the pollution point, and Site B bordered on Site A but was $100 \mathrm{~m}$ from the pollution point. The surface soil samples were (depth of $0-10 \mathrm{~cm}$ ) taken at intervals while walking a "W" pattern over the croplands. In order to investigate the leaching behavior of PCBs in the field, 12 samples were collected at six depths $(0-5$, $5-10,10-15,15-20,20-30$, and $30-50 \mathrm{~cm}$ below surface) from two non-croplands at Sites A and B. All the soil samples were air-dried, ground and sieved to pass a $80 \mathrm{mesh}$, stored in sealed glass containers, and frozen in refrigerator until analysis. The rice was sampled from the same field as the soil samples, and all the samples including different tissues such as grain, stalk, husk and leaves were stored in refrigerator until analysis.

Particulate and vapor samples were taken simultaneously using a medium-volume $(1201 / \mathrm{min})$ and low-volume air samplers $(0.5 \mathrm{l} / \mathrm{min})$ equipped with a filter and glass wool followed by a absorption tube containing $10 \mathrm{ml} \mathrm{N}, \mathrm{N}$-dimethylformamide to collect 
Table 1

Sampling location, date and characteristics for study in the paddy field, WenTai area

\begin{tabular}{|c|c|c|c|c|c|}
\hline Sample & Sampling medium & Sample location ${ }^{\mathrm{a}}$ & Characteristic & Depth (cm) & Date \\
\hline $\mathrm{S} 1$ & Soil & Site A & Cropland & $0-10$ & 1993 \\
\hline G1 & Grain of rice & Sites A and B & Cropland & & 1993 \\
\hline $\mathrm{T} 1$ & Stalk or rice & Sites A and B & Cropland & & 1993 \\
\hline $\mathrm{H} 1$ & Husk of rice & Sites A and B & Cropland & & 1993 \\
\hline $\mathrm{L} 1$ & Leaves of rice & Sites A and B & Cropland & & 1993 \\
\hline $\mathrm{S} 3$ & Soil & Site A & Cropland & $0-10$ & 1997 \\
\hline $\mathrm{S} 4$ & Soil & Site B & Cropland & $0-10$ & 1997 \\
\hline $\mathrm{G} 2$ & Grain of rice & Sites A and B & Cropland & & 1997 \\
\hline $\mathrm{H} 2$ & Husk of rice & Sites A and B & Cropland & & 1997 \\
\hline S5 & Soil & Site A & Cropland & $0-10$ & 1999 \\
\hline S6 & Soil & Site B & Cropland & $0-10$ & 1999 \\
\hline G3 & Grain of rice & Sites A and B & Cropland & & 1999 \\
\hline $\mathrm{T} 3$ & Stalk of rice & Sites A and B & Cropland & & 1999 \\
\hline H3 & Husk of rice & Sites A and B & Cropland & & 1999 \\
\hline L3 & Leaves of rice & Sites A and B & Cropland & & 1999 \\
\hline S7 & Soil & Site A & Non-cropland & $0-5$ & 1999 \\
\hline S8 & Soil & Site A & Non-cropland & $5-10$ & 1999 \\
\hline S9 & Soil & Site A & Non-cropland & $10-15$ & 1999 \\
\hline $\mathrm{S} 10$ & Soil & Site A & Non-cropland & $15-20$ & 1999 \\
\hline $\mathrm{S} 11$ & Soil & Site A & Non-cropland & $20-30$ & 1999 \\
\hline $\mathrm{S} 12$ & Soil & Site A & Non-cropland & $30-50$ & 1999 \\
\hline $\mathrm{S} 13$ & Soil & Site B & Non-cropland & $0-5$ & 1999 \\
\hline S14 & Soil & Site B & Non-cropland & $5-10$ & 1999 \\
\hline $\mathrm{S} 15$ & Soil & Site B & Non-cropland & $10-15$ & 1999 \\
\hline S16 & Soil & Site B & Non-cropland & $15-20$ & 1999 \\
\hline $\mathrm{S} 17$ & Soil & Site B & Non-cropland & $20-30$ & 1999 \\
\hline $\mathrm{S} 18$ & Soil & Site B & Non-cropland & $30-50$ & 1999 \\
\hline $\mathrm{A} 1$ & Gaseous & & Rural area & & 1999 \\
\hline $\mathrm{A} 2$ & Gaseous & & Rural area & & 1999 \\
\hline A3 & Gaseous & & Residential & & 1999 \\
\hline $\mathrm{P} 1$ & Particle & & Rural area & & 1999 \\
\hline $\mathrm{P} 2$ & Particle & & Rural area & & 1999 \\
\hline P3 & Particle & & Residential area & & 1999 \\
\hline
\end{tabular}

${ }^{\text {a }}$ Sampling location Site A: nearby the pollution source, Site B: bordered on Site A, but was $100 \mathrm{~m}$ from the pollution point.

particle- and gas-phase PCBs, respectively (Jing et al., 1992).

\subsection{Extraction}

Analytical procedure for PCBs in soil was described in detail elsewhere (Chu et al., 1996) and briefly described here.

Before the extraction, surrogate containing 3,5-dichlorobiphenyl (International Union of Pure and Applied Chemistry (IUPAC) no. 14) and $2,2^{\prime}, 3,3^{\prime}, 4,4^{\prime}, 5$, $5^{\prime}, 6,6^{\prime}$-decachlorobiphenyl (IUPAC no. 209) was added to the samples.
For determination of PCBs in soil and rice samples, about 5-10 g finely ground sub-sample was homogenized with anhydrous sodium sulfate $\left(\mathrm{Na}_{2} \mathrm{SO}_{4}\right)$ until free flowing powder was obtained. The sample was then extracted with $3 \times 20 \mathrm{ml}$ hexane/acetone $(1 / 1, \mathrm{v} / \mathrm{v})$ by ultrasonication and separated by centrifuging, then the extract was concentrated in Kudema-Danish (KD) apparatus to about $3 \mathrm{ml}$ for further purification.

For determination of PCBs in the particulate-phase, the filters was Soxhlet extracted for $24 \mathrm{~h}$ with $100 \mathrm{ml}$ hexane/acetone $(1 / 1, v / v)$. The extract was concentrated, and the solvent was exchanged to hexane. For determination of PCBs in gas-phase, the 
sampling solution of $N, N$-dimethylformamide was transferred to a separatory funnel with another $5 \mathrm{ml}$ $\mathrm{N}, \mathrm{N}$-dimethylformamide, then $50 \mathrm{ml} \quad 3 \% \mathrm{Na}_{2} \mathrm{SO}_{4}$ aqueous solution and $10 \mathrm{ml}$ hexane was added to the funnel. After mixing and separation, the lower layer was discarded and the upper organic phase was extracted three times by the same procedure, The extract was dried with anhydrous $\mathrm{Na}_{2} \mathrm{SO}_{4}$ and then concentrated to $0.2 \mathrm{ml}$ for gas chromatographic analysis.

\subsection{Clean-up of PCB congeners}

To clean-up the samples, concentrated sulfuric acid (volume $2 \mathrm{ml}$ ) was vigorously shaken with the extract in a test tube to eliminate interfering co-extractants and macromolecules. After centrifugation the acid phase was discarded. The procedure was repeated several times until the acid phase remained colorless. The extract was then washed with $2 \% \mathrm{NaCl}$ aqueous solution, dried with anhydrous $\mathrm{Na}_{2} \mathrm{SO}_{4}$ and concentrated to about $1 \mathrm{ml}$.

For the soil and rice samples, fractionation was done with alumina-silver nitrate modified silica gel chromatography column. After the sample was transferred onto the column, PCB was eluted from the column with hexane in the first $150 \mathrm{ml}$ fraction. The fraction was concentrated by KD apparatus and under a gentle stream of nitrogen to $0.5 \mathrm{ml}$.

For the determination of PCBs in particulate-phase, the interfering compounds were removed by eluting the extracts through a silica gel column with hexane. The extracts were further concentrated to $0.5 \mathrm{ml}$.

\subsection{Determination of $P C B$ congeners}

Congener-specific PCBs analysis was performed on a Varian 3740A gas chromatograph equipped with ${ }^{63} \mathrm{Ni}$ electron capture detector and SE-54 column $(0.25 \mathrm{~mm} \times 40 \mathrm{~m})$. The carrier gas was nitrogen. The injector and detector temperature were 300 and $350{ }^{\circ} \mathrm{C}$, respectively. The oven temperature program was as follows: $50^{\circ} \mathrm{C}$ hold for $2.0 \mathrm{~min}$, then $4^{\circ} \mathrm{C} / \mathrm{min}$, to $280^{\circ} \mathrm{C}$, hold $20 \mathrm{~min}$. A $1 \mu$ l solution was injected with splitless mode. Data on the chromatogram from GC were collected with a WDL-95 workstation (Dalian Inst. Chem. Phys., China). Aroclor mixture was used for congener identification and quantification (Capel et al., 1985). The identifications were con- firmed by HP 6890 gas chromatograph coupled to a HP 5973 mass spectrometer with select ion mode (SIM).

The PCB concentrations were quantified in comparison with the corresponding external standard calibration solution. Calibration curves were determined by diluting a stock solution and run daily. The following congeners were routinely analyzed in all samples: IUPAC no. $8,19,18 / 17,16 / 32,26 / 25,31 / 28,33,22$, $45,46,52,49,48 / 47,44,37 / 42,41 / 64,40,74,70,66$, $60 / 56,101,99,83,97,87,85,110,82,118 / 108,151$, $146,153,141,137,138,128,178,175,187 / 159,185$, $174,177,172,180$, and 170 . The $\sum$ PCBs referred in this study is the sum of these congeners. Residual water was measured by heating sub-samples in oven at $105^{\circ} \mathrm{C}$ for $24 \mathrm{~h}$ and the results were expressed on a dry weight basis.

\subsection{Quality control and quality assurance}

The detection limit of PCBs in samples was designed to be three time of the values of procedural blanks. The average recoveries for PCBs through the analytical procedures (laboratory treatment) was $78 \%$ as determined by spiking $2 \mu \mathrm{g}$ of Aroclor 1254 in the soil samples, and averaged the recoveries of Aroclor 1254. The recoveries of surrogates in all samples were $61.2-119 \%$ for PCB14 and PCB209, and the standard derivation was $14 \%$.

\section{Results and discussion}

\subsection{The PCBs concentration and congener distribution in soil samples}

Soil samples collected from the pollution point were analyzed for PCBs and the results are given in Table 2. The PCB concentrations ( $\sum$ PCBs) in soils for Site A ranged from $1100 \mathrm{ng} / \mathrm{g}$ in 1993 to $927 \mathrm{ng} / \mathrm{g}$ in 1999, which were significantly higher than those in sediments from Baiyangdian Lake and the Second Songhua River in China (Li et al., 1989; Zhu et al., 1995). Although the higher PCB concentrations in the rice field were much higher than the allowable level of $60 \mathrm{ng} / \mathrm{g}$ approved by the former USSR Ministry of Health in 1991, they were lower than those in some heavily contaminated area of other countries (Bobovnikova et al., 1993). 
Table 2

Concentrations of PCB congeners in soil and rice samples (ng/g DW) from the paddy field, WenTai area

\begin{tabular}{|c|c|c|c|c|c|}
\hline IUPAC no. ${ }^{a}$ & $\mathrm{~S} 1^{\mathrm{b}}$ & S3 & S4 & S5 & S6 \\
\hline 8 & 0.85 & $\mathrm{ND}^{\mathrm{c}}$ & ND & 0.50 & 0.75 \\
\hline 19 & 9.70 & ND & ND & ND & ND \\
\hline $18 / 17$ & 110.6 & ND & ND & 13.45 & 0.27 \\
\hline $16 / 32$ & 32.1 & 0.32 & 1.08 & 2.33 & 0.14 \\
\hline $26 / 25$ & 31.4 & 6.84 & 7.30 & 5.16 & 0.19 \\
\hline $31 / 28$ & 102.1 & 79.89 & 57.00 & 51.09 & 10.16 \\
\hline 33 & 36.4 & 6.52 & 5.11 & 3.16 & 2.89 \\
\hline 22 & 17.9 & 0.96 & ND & 0.42 & 0.47 \\
\hline 45 & 12.8 & ND & ND & 1.86 & ND \\
\hline 52 & 73.0 & 82.76 & 32.96 & 19.06 & 8.38 \\
\hline 49 & 47.5 & 18.09 & 18.93 & 10.56 & 5.66 \\
\hline $47 / 48$ & 37.7 & 18.20 & 13.93 & 12.80 & 4.08 \\
\hline 44 & 58.4 & 63.33 & 50.35 & 18.12 & 6.15 \\
\hline $37 / 42$ & 36.2 & ND & ND & 10.64 & 5.27 \\
\hline $41 / 64$ & 65.0 & 44.58 & 26.24 & 20.40 & 6.83 \\
\hline 40 & 10.0 & 0.80 & 0.54 & 1.94 & 0.28 \\
\hline 74 & 46.5 & 33.06 & 20.03 & 16.79 & 5.81 \\
\hline 70 & 56.3 & 35.98 & 27.01 & 14.09 & 6.33 \\
\hline 66 & 72.5 & 62.19 & 40.38 & 26.08 & 8.62 \\
\hline $60 / 56$ & 37.9 & 16.97 & 10.16 & 12.22 & 0.20 \\
\hline 101 & 28.8 & 56.70 & 29.74 & 93.11 & 25.33 \\
\hline 99 & 16.3 & 34.88 & 17.21 & 61.28 & 15.26 \\
\hline 83 & 1.7 & 7.38 & 3.64 & ND & ND \\
\hline 97 & 9.4 & 26.44 & 13.29 & 48.80 & 13.06 \\
\hline 87 & ND & 25.34 & 46.58 & 88.37 & 9.24 \\
\hline 85 & 63.8 & 20.23 & ND & ND & 9.09 \\
\hline 110 & 26.9 & 65.22 & 33.93 & 96.08 & 29.52 \\
\hline 82 & 5.9 & 18.57 & 9.21 & 35.88 & 5.36 \\
\hline $118 / 108$ & 17.9 & 64.85 & 35.44 & 94.48 & 26.51 \\
\hline 146 & 4.7 & 19.91 & 10.48 & 28.27 & 6.14 \\
\hline 153 & 5.6 & 21.70 & 11.74 & 29.03 & 17.34 \\
\hline 141 & 0.92 & ND & ND & 5.49 & 1.77 \\
\hline 137 & 0.18 & ND & ND & 1.99 & 0.81 \\
\hline 138 & 8.7 & 39.41 & 19.97 & 52.40 & 12.87 \\
\hline 178 & 1.0 & 5.10 & 2.44 & 4.86 & 1.58 \\
\hline 175 & 1.8 & 8.43 & 4.46 & 11.36 & 3.56 \\
\hline $187 / 159$ & 0.4 & 2.13 & 1.19 & 2.22 & 0.78 \\
\hline 128 & 1.40 & 7.91 & 4.17 & 7.60 & 2.07 \\
\hline 185 & 0.48 & 2.56 & 1.36 & 7.60 & 2.07 \\
\hline 174 & 0.41 & 2.35 & 1.35 & 2.88 & 0.78 \\
\hline 177 & 0.93 & 6.33 & 2.94 & 3.56 & 1.02 \\
\hline 172 & 0.10 & 1.00 & 0.76 & 3.89 & 1.12 \\
\hline 180 & 1.1 & 5.91 & 3.24 & ND & ND \\
\hline 170 & 1.3 & 7.23 & 3.97 & 7.71 & 1.62 \\
\hline$\sum \mathrm{PCBs}$ & 1101.4 & 920.08 & 568.15 & 7.34 & 2.01 \\
\hline
\end{tabular}

a The number used to designate each congener by International Union of Pure and Applied Chemistry (IUPAC).

b Sample location see Table 1.

${ }^{\mathrm{c}} \mathrm{ND}$ : not detectable.

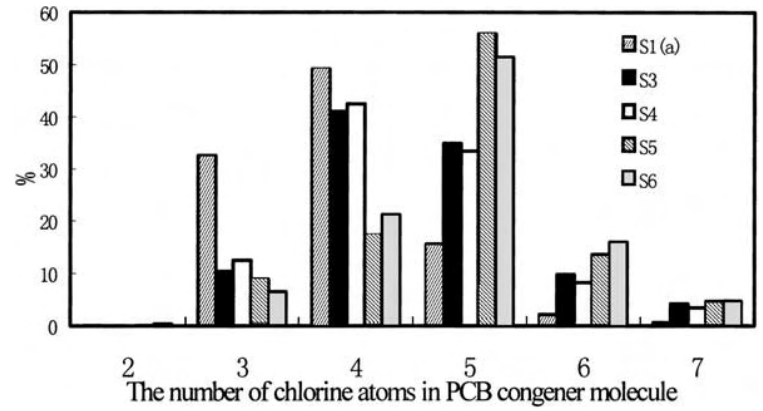

Fig. 1. Relative composition of PCB homologues in a contaminated paddy field of WenTai area, China. A sample location see Table 1.

The $\sum$ PCBs burden of each sample was enriched in the tri- to penta-chlorinated congeners (Fig. 1). These three homolog groups consistently accounted for $>79 \%$ of $\sum$ PCBs in the soil samples. When compared with $\sum$ PCBs in soil samples of S1, S3 and S5, the PCB residue in soil from Site A decreased 16\% over 4 years (1993-1997), but changed little in the last 2 years (1997-1999).

In general, the disappearance of PCBs from the surface soil layer can be described by a simple first-order model:

$C_{\mathrm{i}, t}=C_{\mathrm{i}, 0} \exp \left(-K_{\mathrm{i}} t\right)$

where $C_{\mathrm{i}, 0}$ is the initial concentration of PCB congener in the soil, $C_{\mathrm{i}, t}$ is the concentration of PCB congener in the soil $(\mu \mathrm{g} / \mathrm{kg})$ at time $t$, and $K_{\mathrm{i}}$ is first-order rate constant for disappearance of PCB congener from the soil layer. $C_{\mathrm{i}, t}$ and $t$ are the dependent and independent variables, respectively. $K_{\mathrm{i}}$ 's are parameters estimated from experimental data and dependent on the individual congener. Gan and Berthouex (1994) estimated the disappearance rate for PCB congeners in sludge amended farmland. Di-, tri- and tetra-chlorinated PCBs were found to have half-lives in the range of 4-58 months, while the more highly chlorinated PCBs were more persistent in the soil. Some congener (e.g. congener 180 and 177), the $K$ approximately equals 0.000 . In this study the data were insufficient to fit the model, but it can be seen that the concentrations of most di- to tetra-chlorinated PCB congeners showed a significant decrease compared with those of higher chlorinated PCB congeners (Fig. 1). Recent research has showed that there is a phenomenon of irreversible adsorption 
for hydrophobic organic compounds (HOCs) in soil (Chen et al., 2000; Kan et al., 1997). This means that the desorption was time-varying kinetics, and the release of contaminants from the soils decreased or even stopped after a period (Connaughton et al., 1993). The concentrations of congener 180 and 177 in the soil samples indicated no decrease with time, and even showed some increase. It seemed that during the 6-year period, the paddy field near the pollution point probably had received additional contamination. Therefore, the pattern of highly chlorinated congeners distribution trended to increase.

It is interesting to speculate on the ultimate fate of the PCBs lost from the field. Based on known physico-chemical properties of $\mathrm{PCBs}$, the most likely loss processes are volatilization, leaching and biodegradation. Alcock et al. (1993) showed that volatilization and subsequent long-range transport probably accounted for the bulk of this loss in soil. PCBs normally exhibit relatively low vapor pressures. Solely on the basis of vapor pressure, PCBs would be considered semi-volatile. However, PCBs are relatively insoluble and hydrophobic $\left(\log K_{\text {OW }}=4-9\right)$ and therefore can exhibit significant volatility from aqueous systems. Dunnivant and Elzermqn (1992) determined the Henry Law's Constants (HLCs) for several PCB congeners and calculated all HLCs of 209 congeners, and found that $-\log$ HLC ranged from 3.215 (PCB50) to 4.186 (PCB169). This shows that the highly chlorinated PCBs have lower HLC than low chlorinated PCBs and that the low chlorinated PCBs are more subject to evaporation from aqueous solutions than highly chlorinated PCBs. Some research has reported that significant amount of mono-, di- and tri-chlorinated biphenyls may be volatilized from Aroclar 1248 contaminated sediments at ambient environmental condition (Bushart et al., 1998). It was discovered that PCBs in sediments and particulate were highly susceptible to volatilization upon sediment drying. In the study, the paddy field are usually filled with water in the cultivation process and dried after harvest, therefore, volatilization was inevitable in these field.

It can be seen that even after 6 years the concentrations of PCBs in soil were far from reaching uniform (Table 1). The concentration of PCBs at Site B was about half those at Site A, although the pattern for these samples were similar. Since these two fields were only separated by a narrow track of one-foot width, it is suggested that the transfer of PCBs in soil mainly resulted from the translocation of contaminated soil adsorbed PCBs, as the movement by volatilization and mobility through the pore water are rare.

Leaching is another reason to explain the congener transport in the environment. This study determined the leaching of PCBs in the paddy field. Because the environmental contamination by PCBs is in the form of complex mixture of many congeners and have not a uniform diffusivity, The pattern of PCB congener distribution will change with the sampling depth. Fig. 2 showed the vertical profiles of PCB congeners distribution at the two sites. The PCB concentrations in the soil showed maximal values at the surface and decreasing values sharply with sampling depth. Only trace amounts $(<5 \mathrm{ng} / \mathrm{g})$ of PCBs were observed in the $30-50 \mathrm{~cm}$ soil depth. The PCBs compositions also varied with depth. The low chlorinated PCB congeners were detected in all the samples with different depths, while the concentrations of highly chlorinated PCB congeners in deep layers were below the method detection limit. The equilibrium distribution coefficients $\left(K_{\mathrm{OC}}\right)$ of PCB congeners, which have different substituted chlorine number or position on the two benzene rings, are different from $1.25 \mathrm{E} 5$ to $6.3 \mathrm{E} 6 \mathrm{l} / \mathrm{kg}$ (Jepsen and Lick, 1999). This may result in their different mobility in the soil. In general, a greater $K_{\mathrm{OC}}$ implies a weaker mobility. A laboratory study also showed that pore water was dominated by low chlorinated PCB congeners and sediment dominated by highly chlorinated congeners (Formica et al., 1988). Therefore, low chlorinated PCBs could migrate deeper soil layers through the pore water.

Furthermore, the alteration of the PCB congeners distribution observed in soil can also be attributed to biodegradation in the environment. The biodegradation and position of chlorine substituted. Biodegradation causes the disappearance of the lower chlorinated PCBs, and the degradation decreases with increasing chlorination (Furukawa et al., 1978).

\subsection{PCBs pollution in air samples}

Data are presented for three sets of PCB mixtures in vapor and particulate collected simultaneously (Table 3). The gaseous-phase and particle-phase were characterized by congeners with low chlorinated 
Dichlorinated biphenyls (ng/g)

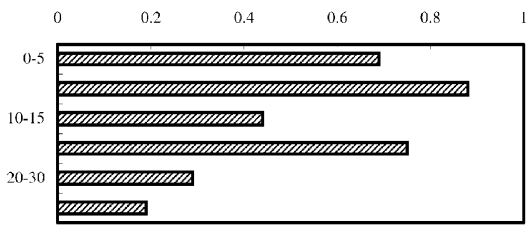

Trichlorinated biphenyls (ng/g)

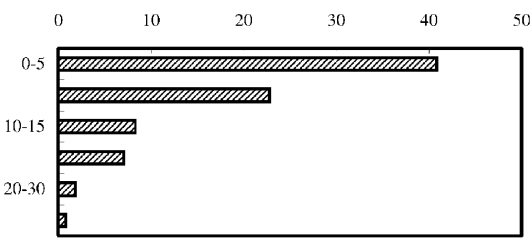

Tetrachlorinated biphenyls (ng/g)

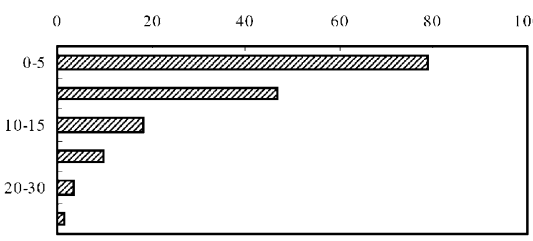

Pentachlorinated biphenyls (ng/g)

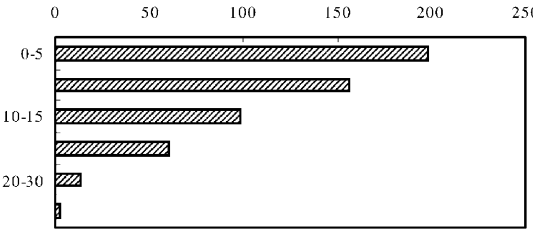

Hexachlorinated bipheny ls (ng/g)

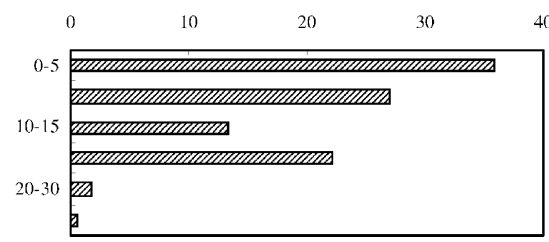

Heptachlorinated biphenyls (ng/g)

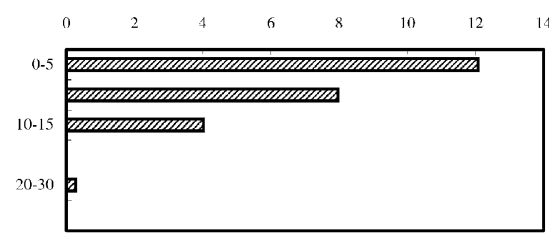

A
Dichlorinated biphenyls (ng/g)

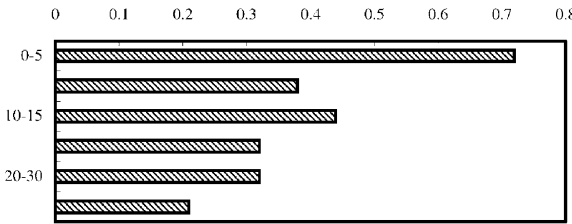

Trichlorinated bipheny Is (ng/g)
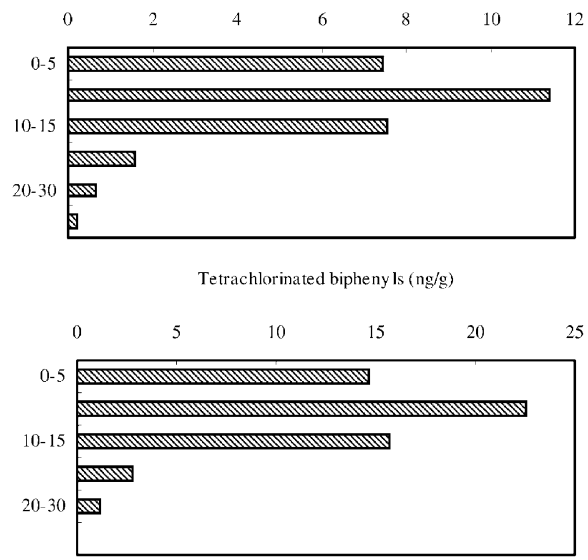

Pentachlorinated biphenyls (ng/g)

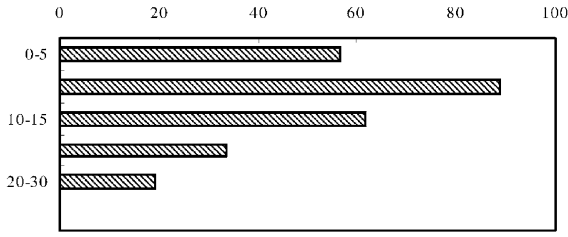

Hexachlorinated bipheny ls (ng/g)

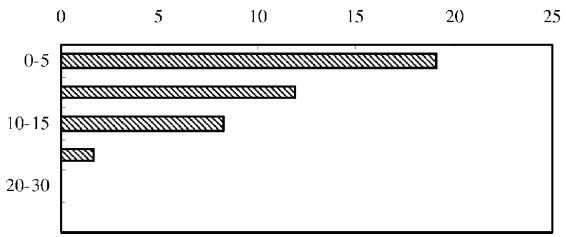

Heptachlorinated biphenyls (ng/g)

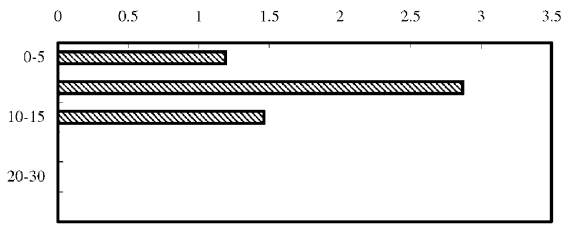

B

Fig. 2. PCBs distribution in the different depth soils: (A) no. 1; (B) no. 2. 
Table 3

The concentrations of PCB congeners in the gaseous-phase and particle-phase $\left(\mathrm{ng} / \mathrm{m}^{3}\right)$

\begin{tabular}{|c|c|c|c|c|c|c|}
\hline \multirow[t]{2}{*}{ IUPAC no. } & \multicolumn{3}{|c|}{ Gaseous-phase } & \multicolumn{3}{|c|}{ Particle-phase } \\
\hline & $\mathrm{A} 1^{\mathrm{a}}$ & $\mathrm{A} 2$ & A 3 & $\mathrm{P} 1$ & $\mathrm{P} 2$ & P3 \\
\hline 4 & 25.3 & 26.0 & 51.2 & 2.53 & 0.13 & 2.25 \\
\hline 7 & 103.6 & 43.0 & 115.7 & 1.00 & 0.05 & 0.96 \\
\hline 8 & $\mathrm{ND}^{\mathrm{b}}$ & ND & ND & 1.66 & 0.07 & 1.74 \\
\hline $18 / 17$ & ND & ND & ND & 0.78 & 0.34 & 1.23 \\
\hline $16 / 32$ & ND & ND & ND & 0.92 & 0.15 & 1.20 \\
\hline $31 / 28$ & 107.8 & 51.6 & 114.4 & 0.20 & 0.04 & 0.40 \\
\hline 33 & 18.8 & 5.70 & 131.6 & 0.02 & 0.04 & 0.03 \\
\hline 22 & 5.33 & 2.92 & 4.84 & ND & ND & ND \\
\hline 52 & 66.6 & 27.2 & 71.6 & 0.03 & 0.06 & 0.09 \\
\hline 49 & 21.9 & 9.46 & 24.8 & 0.03 & 0.07 & 0.09 \\
\hline $47 / 48$ & 14.5 & 7.18 & 10.3 & 0.01 & 0.02 & 0.02 \\
\hline $37 / 42$ & 22.7 & 18.2 & 64.7 & ND & ND & ND \\
\hline 74 & 17.2 & ND & 20.0 & ND & ND & ND \\
\hline 70 & 15.5 & ND & 3.60 & ND & ND & $\mathrm{ND}$ \\
\hline 66 & 15.2 & ND & 24.2 & ND & ND & ND \\
\hline $56 / 60$ & 5.94 & ND & 4.11 & ND & ND & ND \\
\hline$\sum \mathrm{PCBs}$ & 440.37 & 191.26 & 641.05 & 7.18 & 0.97 & 8.01 \\
\hline
\end{tabular}

a Sample location see Table 1.

b ND: not detectable.

PCBs. The sum of PCB concentrations in the gaseous phase, which ranged from 191 to $640 \mathrm{ng} / \mathrm{m}^{3}$, was similar to those recorded in the gaseous fluxes for Lake Michigan (Zhang et al., 1999), however the congeners patterns were different from other European measurements in which penta- and hexa-chlorinated biphenyls were observed (Haugen et al., 1999). Particle-phase concentrations of PCBs in this study were very low and $\sum$ PCB ranged between 5 and $35 \mathrm{ng} / \mathrm{m}^{3}$.

The maximum $\sum$ PCB values in the gas-phase and particle-phase (samples A3 and P3, Table 1) were obtained from the residential area nearby the paddy field. There was an important difference in PCB concentrations pattern. The concentrations of individual PCB congeners varied considerably between the gas-phase and particulates. Generally, the values were considerably higher in the gas-phase than in the particle phase. From Table 3, it can be seen that the amount of PCBs on particulates was estimated as low as 1 to $<2 \%$ of total air burden. The lower contribution of particulates to the total concentration of PCBs in the air samples has also been reported in other studies (Duinker and Bouchertall, 1989).

\subsection{The rice uptake of $P C B$ s}

The various rice tissues were analyzed for PCBs (see Table 4). The PCBs samples of rice stalk and leaves were collected in 1993 and 1999, and those of grain and husk collected in 1993, 1997 and 1999. The PCB concentrations in the rice tissues ranged from ca. 1.8 to $130 \mathrm{ng} / \mathrm{g} \mathrm{DW}$, which was lower than those in the vegetables from the area of a capacitor plant in Serpukhov, Russia (Bobovnikova et al., 1993). The distributions of PCBs in rice tissues were similar in the samples of 1993 and 1999. PCBs concentrations in the rice tissues increased in the order: grain $<$ stalk $<$ husk $<$ leaves. The maximum PCB concentrations (as much as 30-50 times in grain) were observed in the leaves. Leaves are exposed to atmosphere and can concentrate the contaminants from dry gaseous deposition, dry particle bound deposition and wet deposition. There was insignificant PCBs in the rice grain. The concentrations in grain were somewhat less than those found in wheat (Triticu aestivum L.), rye (Secale cerea L.) and barley (Hordeum valgare L.) harvested in a 1972-1974 investigation in Germany, while PCBs were found in some samples at 10-130 ng/g DW (Arrifai and Acker, 1975).

Webber et al. (1994) found that there were differences among crops from PCB accumulation. Other workers also observed that the concentrations of PCB congeners differed greatly in various parts of vegetables (Chewe et al., 1997). Offenbaecher (1992) found an obvious PCB transfer from soil to carrots (Daucus carotavar sativa DC) especially with a higher enrichment of PCB no. 28 than no. 52. Much of the uptake was adsorption on the surfaces of root and small amounts of PCBs were found in the peeled fruit and the carrot foliage (O'Connor et al., 1990). In fact, PCBs in soil are very immobile and most of the PCBs in root may be adsorbed on the surface and not actually accumulated by the plant, therefore there is little translocation (O'Connor et al., 1990). However, volatilization of PCB from soil, landfills, road oil and other sources can result in measurable atmospheric pollution. It was reported that atmospheric deposition was thought to be responsible for $58-90 \%$ of Lake Superior and Michigan's PCB burden (Eisenreich et al., 1981; Jeremiason et al., 1994). Various lines of evidence indicated that polynuclear aromatic hydrocarbons (PAHs) concentrations in vegetation can 
Table 4

Concentration of PCBs congeners in rice samples $\left(\mathrm{ng} / \mathrm{g}^{1}\right)^{\mathrm{a}}$

\begin{tabular}{|c|c|c|c|c|c|c|c|c|c|c|}
\hline IUPAC & G1 & $\mathrm{T} 1$ & H1 & L1 & G2 & $\mathrm{H} 2$ & G3 & $\mathrm{T} 3$ & H3 & L3 \\
\hline 4 & $\mathrm{ND}^{\mathrm{b}}$ & ND & ND & ND & ND & ND & ND & 0.26 & 0.22 & 0.33 \\
\hline 7 & ND & ND & ND & ND & ND & ND & ND & ND & ND & 0.02 \\
\hline 8 & ND & 0.51 & 0.90 & 1.0 & ND & ND & 0.22 & 0.76 & 0.93 & 0.53 \\
\hline 19 & ND & ND & ND & ND & ND & ND & ND & ND & ND & ND \\
\hline $18 / 17$ & 0.13 & 0.25 & 5.80 & 0.55 & ND & ND & 0.06 & 0.27 & 0.18 & 0.37 \\
\hline $16 / 32$ & 0.03 & 0.87 & 2.90 & 1.20 & 0.29 & 1.83 & ND & 0.07 & ND & 0.14 \\
\hline $26 / 25$ & 0.37 & 0.55 & 1.49 & 1.80 & 0.13 & ND & 0.04 & 0.18 & 0.20 & 0.20 \\
\hline $31 / 28$ & 0.39 & 3.00 & 7.20 & 1.90 & 1.28 & 3.49 & 0.08 & 0.05 & 0.52 & 2.77 \\
\hline 33 & ND & 0.60 & 1.60 & 2.10 & 0.54 & 2.27 & ND & 0.38 & 0.41 & 0.52 \\
\hline 22 & ND & 0.31 & 0.76 & 0.77 & 0.09 & 0.13 & ND & ND & ND & ND \\
\hline 45 & ND & ND & 0.42 & 0.08 & ND & ND & ND & 0.04 & ND & ND \\
\hline 52 & 0.26 & 1.70 & 2.20 & 11.60 & 4.33 & 12.42 & ND & ND & 0.26 & 0.77 \\
\hline 49 & 0.05 & 0.84 & 1.00 & 6.60 & 0.77 & ND & ND & 0.56 & 0.19 & 0.57 \\
\hline $47 / 48$ & 0.23 & 0.75 & 1.40 & 4.50 & ND & ND & ND & ND & 0.20 & 0.40 \\
\hline 44 & 0.04 & 1.10 & 1.60 & 9.60 & 0.24 & 2.61 & ND & 0.42 & 0.22 & 0.51 \\
\hline $37 / 42$ & 0.08 & 0.68 & 0.79 & 3.40 & ND & ND & ND & ND & 0.06 & 0.33 \\
\hline $41 / 64$ & 0.04 & 0.81 & 1.60 & 6.80 & 0.64 & 1.20 & 0.04 & 0.17 & 0.21 & 0.84 \\
\hline 40 & ND & ND & 0.29 & ND & ND & 0.27 & ND & ND & 0.03 & 0.09 \\
\hline 74 & 0.11 & 0.82 & 1.00 & 8.30 & 1.49 & ND & 0.02 & 0.11 & 0.12 & 0.73 \\
\hline 70 & 0.12 & 0.94 & 1.60 & 12.10 & 1.71 & ND & 0.02 & 0.06 & 0.09 & 0.82 \\
\hline 66 & 0.19 & 1.60 & 2.40 & 19.70 & 3.73 & 3.30 & 0.03 & 0.09 & 0.14 & 1.72 \\
\hline $60 / 56$ & 0.10 & 0.36 & 1.20 & 0.64 & 1.08 & 0.56 & 0.01 & 0.05 & 0.07 & 0.84 \\
\hline 101 & 0.01 & 0.31 & 1.70 & 5.00 & 1.61 & 1.25 & ND & 0.28 & 0.41 & 2.35 \\
\hline 99 & ND & 0.33 & 0.52 & 3.30 & 1.04 & 1.26 & ND & ND & 0.24 & 1.70 \\
\hline 83 & ND & ND & ND & 0.25 & ND & ND & ND & ND & ND & ND \\
\hline 97 & ND & 0.13 & ND & 2.10 & 1.19 & 0.88 & ND & 0.09 & ND & 1.35 \\
\hline 87 & ND & 0.11 & 0.15 & 1.80 & 2.64 & 2.41 & 0.23 & 0.85 & 0.78 & 5.37 \\
\hline 85 & ND & 0.25 & ND & 1.60 & ND & ND & ND & ND & ND & ND \\
\hline 110 & 0.08 & 0.31 & 1.20 & 5.30 & 3.95 & 1.22 & 0.20 & 0.71 & 0.76 & 2.74 \\
\hline 82 & ND & 0.07 & 0.24 & 0.69 & 1.14 & ND & 0.42 & 0.84 & 0.63 & 1.51 \\
\hline $118 / 108$ & 0.04 & 0.32 & 0.98 & 5.90 & 4.37 & 1.03 & 0.15 & 0.34 & 0.26 & 2.19 \\
\hline 146 & ND & 0.07 & 0.47 & 2.00 & 1.46 & ND & ND & ND & ND & 0.59 \\
\hline 153 & 0.04 & 0.08 & 0.34 & 1.30 & 1.32 & 0.30 & 0.04 & 0.10 & 0.10 & 0.54 \\
\hline 141 & ND & ND & 0.06 & 0.38 & ND & ND & ND & ND & ND & 0.10 \\
\hline 137 & ND & ND & 0.03 & 0.14 & ND & ND & ND & ND & ND & ND \\
\hline 138 & ND & 0.12 & 0.89 & 3.60 & 2.94 & 0.54 & ND & 0.10 & ND & 0.90 \\
\hline 178 & ND & ND & 0.20 & 0.34 & ND & ND & ND & ND & ND & ND \\
\hline 175 & ND & ND & ND & 0.46 & ND & ND & ND & ND & ND & ND \\
\hline $187 / 159$ & ND & ND & ND & ND & ND & ND & ND & ND & ND & ND \\
\hline 128 & ND & ND & 0.19 & 0.66 & 0.51 & ND & ND & ND & ND & 0.16 \\
\hline 185 & ND & ND & ND & 0.14 & ND & ND & ND & ND & ND & ND \\
\hline 174 & ND & ND & ND & 0.14 & ND & ND & ND & ND & ND & ND \\
\hline 177 & ND & ND & 0.10 & 0.37 & ND & ND & ND & ND & ND & ND \\
\hline 180 & ND & ND & 0.07 & 0.35 & ND & ND & ND & ND & ND & 0.08 \\
\hline 170 & ND & ND & 0.09 & 0.41 & ND & ND & ND & ND & ND & ND \\
\hline$\sum \mathrm{PCBs}$ & 2.34 & 17.700 & 43.57 & 129.00 & 38.50 & 36.98 & 1.55 & 6.78 & 7.24 & 32.08 \\
\hline
\end{tabular}

${ }^{\text {a }}$ Sample location see Table 1.

${ }^{\mathrm{b}} \mathrm{ND}$ : not detectable. 


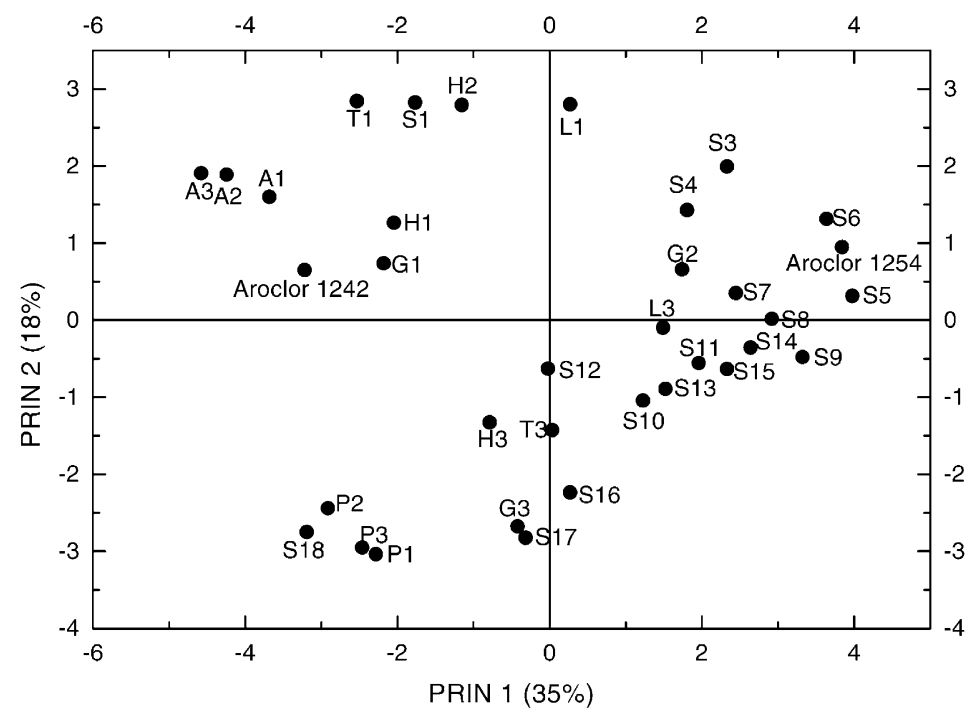

Fig. 3. Scores of the first two principal components of normalized PCBs data in a contaminated paddy field of WenTai area samples.

be used as an indication of atmospheric deposition directly on the above-ground plant portions, and that uptake and translocation of soil-bound PAHs were negligible. With roughly similar properties between PAHs and PCBs, it is presumed that PCBs would show a similar result.

The results indicated that the total concentration of PCBs in soil from Site B was about half that in soil from Site A, the of PCBs contamination in leaves collected in the two fields were not significantly different. This also suggested that PCB concentrations in the rice are not greatly dependent on $\mathrm{PCB}$ concentrations in the soil. However, PCB concentrations in the rice leaves cannot be overlooked if livestock feed on them, as then PCBs can be bioconcentrated in human bodies through the food chain. From this point, the contaminated soils still represent a potential hazard to human health.

\subsection{Principal components analysis (PCA)}

For further data evaluation, environmental workers are interested in applying multivariate statistical methods to evaluate patterns of organic compounds in the environment (Swerev and Ballschmiter, 1989). These methods can reduce a complex dataset to a few principle components that represent the main composition of the sample. In this study, a multivariate statistical technique-principal component analysis (PCA) with the SAS software was utilized to characterize PCBs profiles in the environmental samples. Sample data were normalized with the sum of PCB concentrations. The PCB concentrations below the detection limit were set to 0 .

In these kind of plots, similarity of the compositions results in neighboring positions. Fig. 3 and Table 5 illustrate the PCB pattern in the WenTai samples on the principal components. Principal component 1 , accounting for $35.4 \%$ of the variability, represents the degree of chlorination. It is loaded negatively by most di- to tetra-chlorobiphenyls and pos-

Table 5

Accumulated variance (\%) explained by principal components in samples

\begin{tabular}{lll}
\hline Principal components & Proportion & Cumulative \\
\hline PRIN1 & 0.35 & 0.35 \\
PRIN2 & 0.18 & 0.54 \\
PRIN3 & 0.09 & 0.63 \\
PRIN4 & 0.07 & 0.70 \\
PRIN5 & 0.05 & 0.76 \\
PRIN6 & 0.05 & 0.80 \\
PRIN7 & 0.04 & 0.85 \\
PRIN8 & 0.03 & 0.88 \\
PRIN9 & 0.03 & 0.91 \\
PRIN10 & 0.02 & 0.93 \\
\hline
\end{tabular}


itively by most penta- to heptachlorinated-biphenyls. Fig. 3 shows that PCB profile for the samples was clearly distinguished on the first principal component (PC): air and rice samples are all located on the negative side of the first PC, while most of the soil samples are found on the positive side. This indicated that air and rice are characterized by lower chlorinated PCBs and that the soil samples were characterized by higher chlorinated PCBs. The soil samples obtained at the various depths were characterized by different compositions of the mixtures of individual congeners. In Fig. 3, the soil sample point of 1993 was close to that of Aroclor 1242, which means that the contamination in the soil sample had similar congeners distribution with the pollution source, while those of 1997 and 1999 are somewhat toward Aroclor 1254 position, which had more higher chlorinated biphenyl congeners. All these observations indicated that the pattern of PCBs in soils after a few years cannot be considered to reflect the original pollution source. Meanwhile, the soil and rice samples scatter in Fig. 3, indicates that the distribution of PCBs in rice tissues has not direct relationship with soil pollution.

\section{Conclusions}

In conclusion, $\mathrm{PCBs}$ pollution in these paddy fields was quite serious. Even after 6 years the equilibrium of PCBs contamination between the paddy field and the pollution source or and the nearby paddy field was not reached. Although some of the lower chlorinated biphenyls disappeared in the past 6 years, the higher chlorinated biphenyls persisted in the field. The pattern of PCBs in soils could not be considered to reflect the original pollution source. Rice grown in the field was subject to some contamination by PCBs, but it does not appear significantly bioconcentrate PCBs from environmental system like several other plants. PCB concentrations in rice samples were not directly proportional to PCB concentrations in soil.

\section{Acknowledgements}

This work was funded by the Research Foundation of Chinese Academy of Sciences (Bureau of Resources and Environment and Bureau of Basic Studies,
KZ951-B1-209-02), and National Science Foundation of China (29837180). The authors thank Dr. Kejiu Du and Dongli Wang for their assistance in sampling. The authors are grateful to the Hewlett Packard Co. (now Agilent Tech. Co.) for the instrument supports.

\section{References}

Alcock, R.E., Johnston, A.E., McGrath, S.P., Berrow, M.L., Jones, K.C., 1993. Long-term changes in the polychlorinated biphenyl content of UK soils. Environ. Sci. Technol. 27, 1918-1923.

Arrifai, K., Acker, L., 1975. The contamination of grain with polychlorinated biphenyls and hexachlorobenzene. Ber. Getreidechem. Tag., Detmold, 103-110.

Bacci, E., Gaggi, C., 1985. Polychlorinated biphenyls in plant foliage translocation or volatilization from contaminated soils? Environ. Cotam. Toxicol. 35, 673-681.

Bobovnikova, T., Dibtseva, A., Mitroshkov, A., Pleskachevskaya, G., 1993. Ecological assessment of a region with PCB emissions using samples of soil, vegetation and breast milk: a case study. Sci. Total Environ. 139/140, 357-364.

Bush, B., Shane, L.A., Wilson, L.R., Barnard, E.L., Barnes, D.V., 1986. Uptake of polychlorobiphenyl congeners by purple loosestrife (Lythrum salicaria) on the banks of the Hudson river. Arch. Environ. Contam. Toxicol. 15, 285-290.

Bushart, S., Bush, B., Barnard, E.L., Bott, A., 1998. Volatilization of extensively dechlorinated PCBs from historicallycontaminated sediments. Environ. Toxicol. Chem. 17, 19271933.

Capel, P.D., Rapaport, R.A., Eisenreich, S.J., Looney, B.B., 1985. PCBQ: computerized quantification of total PCB and congeners in environmental samples. Chemosphere 14, 439-450.

Chen, W., Kan, A.T., Tomsin, M.B., 2000. Irreversible adsorption of chlorinated benzenes to natural sediments: implication for sediment quality criteria. Environ. Sci. Technol. 34, 385-392.

Chewe, D., Creaser, C.S., Foxall, C.D., Lovetl, A.A., 1997. Validation of a congener specific method for ortho- and non-ortho substituted polychlorinated biphenyls in fruit and vegetable samples. Chemosphere 35, 1399-1407.

Chu, S., Yang, C., Xu, X., 1996. Determination of polychlorinated biphenyl congeners in environmental samples. J. Environ. Sci. $8,57-65$.

Chung, N., Alexander, M., 1998. Differences in sequestration and bioavailability of organic compounds aged in dissimilar soils. Environ. Sci. Technol. 32, 855-860.

Connaughton, D.F., Stedinger, J.R., Lion, L.W., Shuler, M.L., 1993. Description of time-varying desorption kinetics: release of naphthalene from contaminated soils. Environ. Sci. Technol. 27, 2397-2403.

Duinker, J.C., Bouchertall, F., 1989. On the distribution of atmospheric polychlorinated biphenyl congeners between vapor phase, aerosols and rain. Environ. Sci. Technol. 23, 57-62.

Dunnivant, F.M., Elzermqn, A.W., 1992. Quantitative structureproperty relationships for aqueous solubilities and Henry's law constants of polychlorinated biphenyls. Environ. Sci. Technol. $26,1567-1573$. 
Eisenreich, S.J., Looney, B.B., Thornton, J.D., 1981. Airborne organic concentrations in the Great lakes ecosystem. Environ. Sci. Technol. 15, 30-38.

Furukawa, K., Tonomura, A., Kamibazashi, A., 1978. Effect of chlorine substitution on the biodegradability of polychlorinated biphenyls. Appl. Environ. Microbiol. 35, 223-227.

Formica, S.J., Baron, J.A., Thibodeaux, L.J., Vaisaraj, K.T., 1988. PCB transport into lake sediments: conceptual model and laboratory simulation. Environ. Sci. Technol. 22, 1435-1440.

Gan, D.R., Berthouex, P.M., 1994. Disappearance and crop uptake of PCBs from sludge-amended farmland. Water Environ. Res. $66,54-69$.

Haugen, J.-E., Wania, F., Lei, Y.D., 1999. Polychlorinated biphenyls in the atmosphere of south Norway. Environ. Sci. Technol. 33, 2340-2345.

Iwata, H., Tanabe, S., Sakai, N., Nishimura, A., Tatsukawa, R., 1994. Geographical distribution of persistent organochlorines in air, water, and sediments from Asia and Oceania, and their implication for global redistribution from lower latitudes. Environ. Pollut. 85, 15-33.

Jan, J., Adamic, M., 1991. Polychlorinated biphenyl residues in foods from a contaminated region Yugoslavia. Food Addit. Contam. 8, 505-512.

Jepsen, R., Lick, W., 1999. Nolinear and interactive effects in the sorption of hydrophobic organic chemicals by sediments. Environ. Toxicol. Chem. 18, 1627-1636.

Jeremiason, J.D., Hornbuckie, K.C., Eisenreich, S.J., 1994. PCBs in Lake Superior, 1978-1992: decreases in water concentrations reflect loss by volatilization. Environ. Sci. Technol. 28, 903914.

Jing, Z.Y., Li, Y.H., Feng, X.B., Chen, R.L., 1992. The analysis of PCBs in the air by GC. Collection Environ. Sci. 13, 40-43.

Kan, A.T., Fu, G., Hunter, M.A., Tomson, M.B., 1997. Irreversible adsorption of naphthalene and tetrachlorobiphenyl to Lura and surrogate sediments. Environ. Sci. Technol. 31, 2176-2185.

Kannan, K., Tanabe, S., Williams, R.J., Tatsukawa, R., 1994. Persistant organochlorine residues in foodstuffs from Australia, Papua New Guinea and the Solomon Islands: contamination levels and human dietary exposure. Sci. Total Environ. $153(1 / 2), 29-49$.

Li, M.X., Yue, G.C., Gao, F.M., Du, Y.G., 1989. Transport and distribution of PCBs and organochlorine pesticides in the Second Songhua River. Environ. Chem. 8, 51-54.
Muller, J.F., Hulster, A., Papke, O., Ball, M., Marschner, H., 1993. Transfer pathways of PCDD/PCDF to fruits. Chemosphere 27, 195-201.

Ocker, H.D., Eich, E., 1992. In: Hans-Dieter, O. (Ed.), Occurrence of Polychlorinated Biphenyls (PCB) in Cereals. Rueckstaende Kontam, Getreide Getrerideprod, pp. 95-111.

O’Connor, G.A., Kiehl, D., Eiceman, G.A., Ryan, J.A., 1990. Plant uptake of sludge-borne PCBs. J. Environ. Qual. 19, 113-118.

Offenbaecher, G., 1992. The PCB transfer from soil into plants depending on supply and degree of chlorination. Comm. Eur. Communities, [Rep.]EUR (1992), EUR 14236, Eff. Org. Contam. Sewage Sludge Soil Fertil., Plants Anim., pp. 90-102.

Schecter, A., Cramer, P., Boggess, K., Stanley, J., Olson, J.R., 1997. Levels of dioxins, dibenzofurans, $\mathrm{PCB}$ and DDE congeners in pooled food samples collected in 1995 at supermarkets across the United States. Chemosphere 34 (5-7, Chlorinated Dioxins, PCB and Related Compounds, 1995), 1437-1447.

Shane, L.A., Bush, B., 1989. Accumulation of polychlorobiphenyl congeners and $p, p^{\prime}$-DDE at environmental concentrations by corn and beans. Ecotoxicol. Environ. Safety 17, 38-46.

Suzuki, M., Aizawam, N., Okano, G., Takahashi, T., 1977. Translocation of polychlorobiphenyls in soil into plants: a study by a method of culture of soybean sprouts. Arch. Environ. Contam. Toxicol. 5, 343-352.

Swerev, M., Ballschmiter, K., 1989. Application of multivariate analysis to the determination of PCBs in fly ash from municipal incinerators. Chemosphere 18, 2213-2227.

Theelen, R.M.C., Liem, A.K.D., Slob, W., van Wijnen, J.H., 1993. Intake of 2,3,7,8-chlorin-substituted dioxins, furans, and planar PCBs from food in The Netherlands: median and distribution. Chemosphere 27 (9), 1625-1635.

Webber, M.D., Pietz, R.I., Granato, T.C., Svoboda, M.L., 1994. Plant uptake of PCBs and other organic contaminants from sludge-treated coal refuse. J. Environ. Qual. 23, 1019-1026.

WHO, 1993. WHO, Geneva, Environmental Health Criteria 140, Polychlorinated Biphenyls and Terphenyls, 1993.

Zhang, H., Eisenreich, S.J., Franz, T.R., Baker, J.E., Offenberg, J.H., 1999. Evidence for increased gaseous PCB fluxes to Lake Michigan from Chicago. Environ. Sci. Technol. 33, 21292137.

Zhu, X.R., Wang, Y.Z., Wang, D.L., Wang, Z.J., Peng, A., Södergren, A.G., Mu, H.L., Wesén, C., 1995. PCBs pollution in Baiyangdian Area. Acta Scientiae Circumstantiae. 15, 86-91. 